\title{
Black Carbon Aerosol Characteristics and Its Radiative Impact over Nainital: A High-Altitude Station in the Central Himalayas
}

\author{
A. K. SRIVASTAVA ${ }^{1 * \#}$, P. PANT ${ }^{2}$, U. C. DUMKA ${ }^{2}$, P. HEGDE ${ }^{3 \#}$ \\ ${ }^{1}$ Indian Institute of Tropical Meteorology (Branch), Prof Ramnath Vij Marg, New Delhi, India \\ ${ }^{2}$ Aryabhatta Research Institute of Observational Sciences (ARIES), Nainital, India \\ ${ }^{3}$ Space Physics Laboratory, Vikram Sarabhai Space Centre (VSSC), Trivandrum, India
}

\begin{abstract}
Ground-based measurements of aerosol black carbon (BC), from a high altitude location at Nainital in the central Himalayas (during June 2006 to May 2007), were used to study its temporal variability and impact on the atmospheric radiative forcing. Diurnal variation of $\mathrm{BC}$ mass concentration shows single enhanced peak in the late afternoon hour. The peak is rather pronounced in winter months due to shallow and stable boundarylayer condition, which is largely associated with low surface temperature. The mean BC mass concentrations were found to be as $\sim 0.6( \pm 0.2), 1.4( \pm 0.1), 1.2( \pm 0.3)$ and $1.5( \pm 0.2) \mu \mathrm{g} \mathrm{m}^{-3}$ during monsoon, post-monsoon, winter and spring periods, respectively while its maximum value was $\sim 1.8( \pm 0.8) \mu \mathrm{g} \mathrm{m}^{-3}$ during April. The prevailing winds revealed to facilitates the transport of $\mathrm{BC}$ from the distant sources to the observing site. A radiative transfer model was used in conjunction with an aerosol optical model to estimate the $\mathrm{BC}$ radiative forcing over the station. Results show $\mathrm{BC}$ forcing at the top-of-atmosphere (TOA), surface and in the atmosphere varies between about +3 to +7 , -6 to -14 and +8 to $+21 \mathrm{Wm}^{-2}$, respectively which is more pronounced during spring then during monsoon depending upon $\mathrm{BC}$ mass loading. The positive atmosphere forcing represents a considerable amount of heating to the lower atmosphere and has been conjectured as potential factor causing global warming. The estimated heating rate of the lower atmosphere over the station was found to be ranging from $0.24 \mathrm{Kday}^{-1}$ during monsoon to $0.58 \mathrm{Kday}^{-1}$ during spring season.
\end{abstract}

\# This work was initiated during author's tenure at ARIES, Nainital.

\section{Introduction}

The total $\mathrm{BC}$ emission from India constitutes a large fraction as far as the total global emissions is concerned (Reddy and Venkataraman 1999) and shows large spatio-temporal variability due to varied land-use and agricultural practices. Therefore, monitoring of $\mathrm{BC}$ aerosols across various parts of the country is important to assess the radiative effects on regional as well as global scale as it exhibits largest uncertainty in constraining to the radiative forcing of aerosols (Ramachandran and Rajesh 2007). Numerous measurements of BC aerosols and its impact assessments are being reported at the various locations in India by Babu et al. (2002); Babu and Moorthy (2002); Latha and Badarinath (2003); Tripathi et al. (2005); Ramachandran and Rajesh (2007); Safai et al. (2007); Sreekanth et al. (2007). However, most of these studies focused to either urban/semi-urban landmass or oceans adjacent to densely populated coastal belt. Investigations from remote, sparsely inhabited regions have the importance of providing a sort of background against which the urban impacts can be compared. In this perspective, observations 
from high altitude stations have a special significance as the aerosols in this region provide a "far-field picture", quite away from the potential sources (Pant et al. 2006).

The present study aims to show BC aerosol characteristics over a high altitude station at Nainital ( 1958 $\mathrm{m}$ above mean sea level, msl) situated in the central Himalayas. Apart from the basic characteristics, the key focus of the present study is on to study the impact of BC aerosols on radiative forcing over the station.

\section{Site description}

Observations were carried out at Manora Peak $\left(29.4^{\circ} \mathrm{N}, 79.5^{\circ} \mathrm{E}, 1958 \mathrm{~m}\right.$ above msl), Nainital, located in the central Himalayas. The north and northeast of Manora Peak has sharply undulating topography of Himalayan mountain ranges; however, the south-west side has low elevated plain land merging into the Ganga Basin. Due to its large elevation, associated with a very low atmospheric boundary layer height, this site may be considered to be as a free tropospheric site (Srivastava et al. 2010). As the site is devoid of any major pollution (Sagar et al. 2004; Pant et al. 2006), the investigation from such a remote, sparsely inhabited regions have the importance of providing a sort of background level against which the impact of aerosol loading from far-off regions can be assessed.

\section{Instrumentation and data analysis}

Measurements of BC aerosol mass concentration were carried out at Nainital, using a seven channel Aethalometer (Model AE-42) of Magee Scientific Company, USA. The extensive database with a temporal resolution of 5 minutes, for the period June 2006 to May 2007 is used in the present study. Aethalometer measures BC mass concentrations in the wavelength range of 370 to $950 \mathrm{~nm}$. In the present study, BC mass concentration measured at $880 \mathrm{~nm}$ wavelength is considered to represent a true value of $\mathrm{BC}$ in the atmosphere as at this wavelength, $\mathrm{BC}$ is the principal absorber of light while the other aerosol components have negligible absorption at this wavelength (Bodhaine 1995). This is a filter based technique that measures the light attenuation due to particles deposited on to a quartz filter. More details on the instrument and the principle of measurements are available elsewhere (Hansen et al. 1984). Since the standard flow rate of the instrument corresponds to the standard atmospheric temperature of $293 \mathrm{~K}$ and pressure of 1017 $\mathrm{hPa}$, therefore the measured values of $\mathrm{BC}$ were corrected for the mean surface level pressure $(\sim 817 \mathrm{hPa})$ and the hourly measured surface temperature of the station for maintaining the constant flow rate.

\section{Results and discussion}

\section{BC mass concentration}

Figure 1 shows contour plot of monthly-hourly variations of $\mathrm{BC}$ mass concentration illustrating the intensification and deterioration of $\mathrm{BC}$ mass concentration. Although the enhanced patches of $\mathrm{BC}$ mass concentration were observed during November, January and April months but large temporal spreading of enhanced $\mathrm{BC}$ was observed only during the month of April. For the study of seasonal variation of $\mathrm{BC}$ concentration, the data were grouped into four different seasons as 
Monsoon (June, July, August, September), Post Monsoon (October, November), Winter (December, January, February) and Spring (March, April, May). Seasonal mean diurnal variations of surface BC mass concentration along with mean surface temperature is shown in Figure 2 where vertical bars indicate standard deviations in the BC mass concentration from their respective mean. Moderately high temperature was observed during spring and monsoon months, which vary from about 14 to $18^{\circ} \mathrm{C}$ and 17 to $21^{\circ} \mathrm{C}$, respectively whereas during post monsoon and winter surface temperature vary from about 12 to $19^{\circ} \mathrm{C}$ and 7 to $13^{\circ} \mathrm{C}$, respectively.

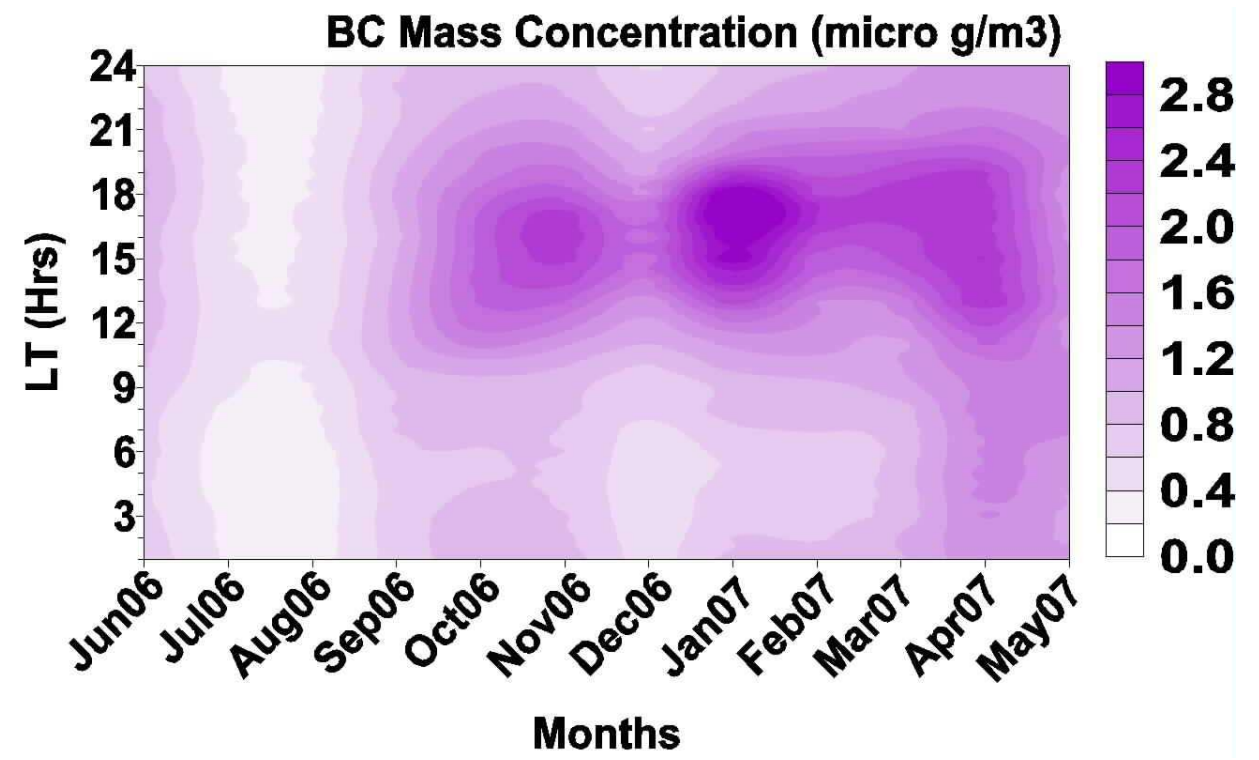

Figure 1: Monthly-hourly variations of surface BC mass concentrations.

A significant diurnal variation in BC mass concentration was observed during the post monsoon, winter and spring periods, which was absent during monsoon with very low magnitude of $\mathrm{BC}$ mass concentrations and it is mainly due to the washout process by rain activities. The trend of diurnal variations with day time high and morning and night time low values of BC mass concentrations over Nainital is quite opposite to other low altitude urban locations as reported by Babu and Moorthy (2002); Latha and Badarinath (2003); Tripathi et al. (2005); Ramachandran and Rajesh (2007); Safai et al. (2007); Sreekanth et al. (2007). In their observations they have reported two significant peaks in BC mass concentrations during morning and night hours, which are largely associated with increased anthropogenic activities and fumigation effect. On the other hand the diurnal variations observed at Nainital, show (Figure 2) lower values of BC mass concentration during morning and night hours and increases slowly thereafter approaching its highest level in the late afternoon (around 17:00 hr local time (LT)) and then decreases more rapidly to reach its low level around midnight. 


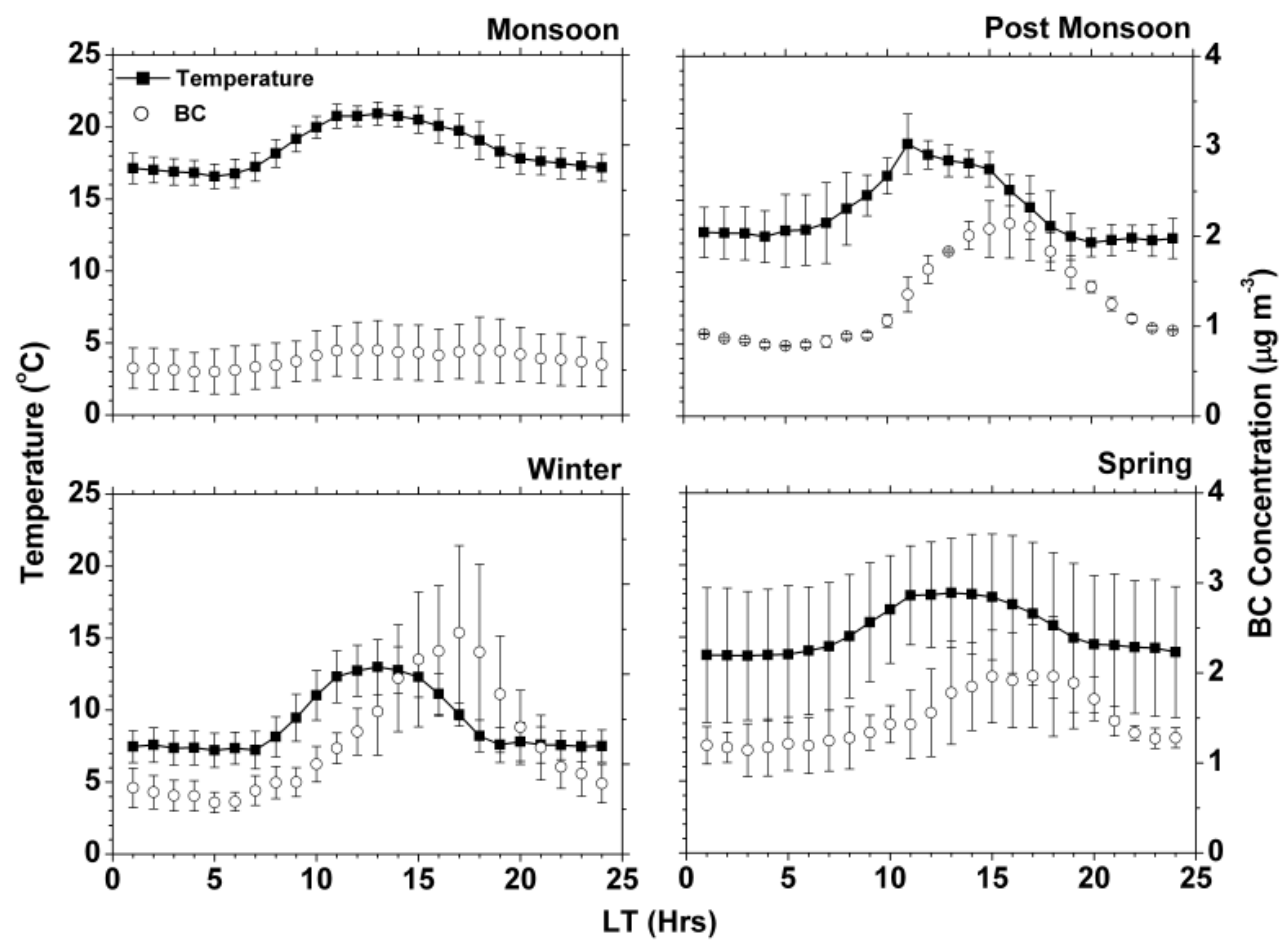

Figure 2: Seasonal diurnal variations of surface $\mathrm{BC}$ mass concentrations and temperature (Vertical bars indicate standard deviations from their respective means)

The late afternoon peak value of $\mathrm{BC}$ mass concentrations during post monsoon, winter and spring months were found to be $\sim 2.1( \pm 0.4), 2.5( \pm 1.0)$ and $2.0( \pm 0.6) \mu \mathrm{g} \mathrm{m}^{-3}$, respectively which is due to the accumulation of $\mathrm{BC}$ aerosols within the nocturnal boundary layer. The peaks are quite prominent in the winter months due to shallow and more stable boundary layer. However, morning hour peaks are not observed over the station, which are mainly due to the absence of locally generated pollution induced by anthropogenic activities. Pant et al. (2006) have observed the similar diurnal pattern of BC mass concentration over Nainital during a land campaign (LCII) held in December 2004 as a part of Indian Space Research Organization-Geosphere Biosphere Program (ISRO-GBP) for aerosol characterization. They have attributed the results mainly due to boundary layer dynamics that brings up the polluted emissions from the underlying valley regions to the high altitude location.

Figure 3 shows monthly mean BC mass concentrations and temperature, measured over Nainital from June 2006 to May 2007. Vertical bars represent standard deviations from their respective means. BC was observed to be started increasing from the month of August when its magnitude was lowest $\sim 0.4( \pm 0.1) \mu \mathrm{g} \mathrm{m}^{-3}$ and reached to the maximum value of $\sim 1.8( \pm 0.8) \mu \mathrm{g} \mathrm{m}^{-3}$ in the month of April. The seasonal mean BC mass concentration was observed to be $\sim 0.6( \pm 0.2), 1.4$ $( \pm 0.1), 1.2( \pm 0.3)$ and $1.5( \pm 0.3) \mu \mathrm{g} \mathrm{m}^{-3}$, with corresponding mean of surface temperature as $\sim 18.5( \pm 1.6), 14.3( \pm 2.3), 9.1( \pm 2.2)$ and $15.5( \pm 1.7)^{\circ} \mathrm{C}$, during monsoon, post monsoon, winter and spring seasons, respectively. 


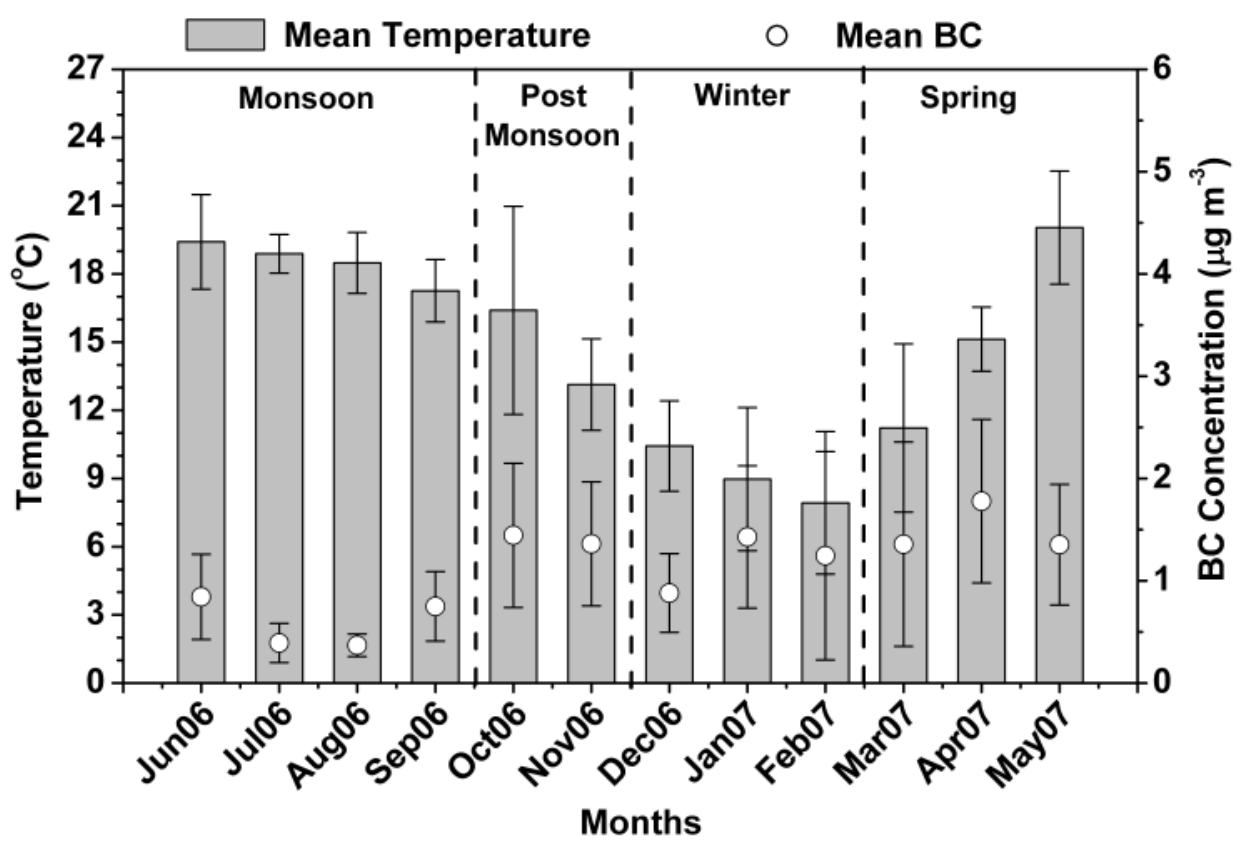

Figure 3: Monthly mean variations of BC mass concentrations and temperature

The other factor that influences the $\mathrm{BC}$ concentration over the station is the surface wind patterns. In order to understand their effect on $\mathrm{BC}$ concentration, the surface wind parameters at the station have been studied. Figure 4 shows monthly mean surface wind speed (WS) in the upper panel and wind direction (WD) in the lower panel from June 2006 to May 2007 where vertical bars on wind speed indicate the standard deviations. Generally, the prevailing surface winds were observed to be from south-westerly direction with the speed varying between 2.1 $( \pm 1.1)$ and $3.8( \pm 1.6) \mathrm{ms}^{-1}$. To the south-west of Nainital is the IGB, which is considered to be a major source of various anthropogenic pollutants including BC. Thus the apportionment probability to increase $\mathrm{BC}$ concentrations over the experimental site is more during the upslope valley winds. To see the association between surface wind and $\mathrm{BC}$ mass concentrations, monthly mean $\mathrm{BC}$ values were plotted along with monthly mean wind speed in the upper panel of Figure 4. By-and-large positive association between these two parameters has been observed except during October and December months when a sharp decrease in wind speed corresponds to an increase in $\mathrm{BC}$ mass concentration and vice-versa. These results are found to be opposite to those observed over other low altitude stations (Ramachandran and Rajesh 2007). 


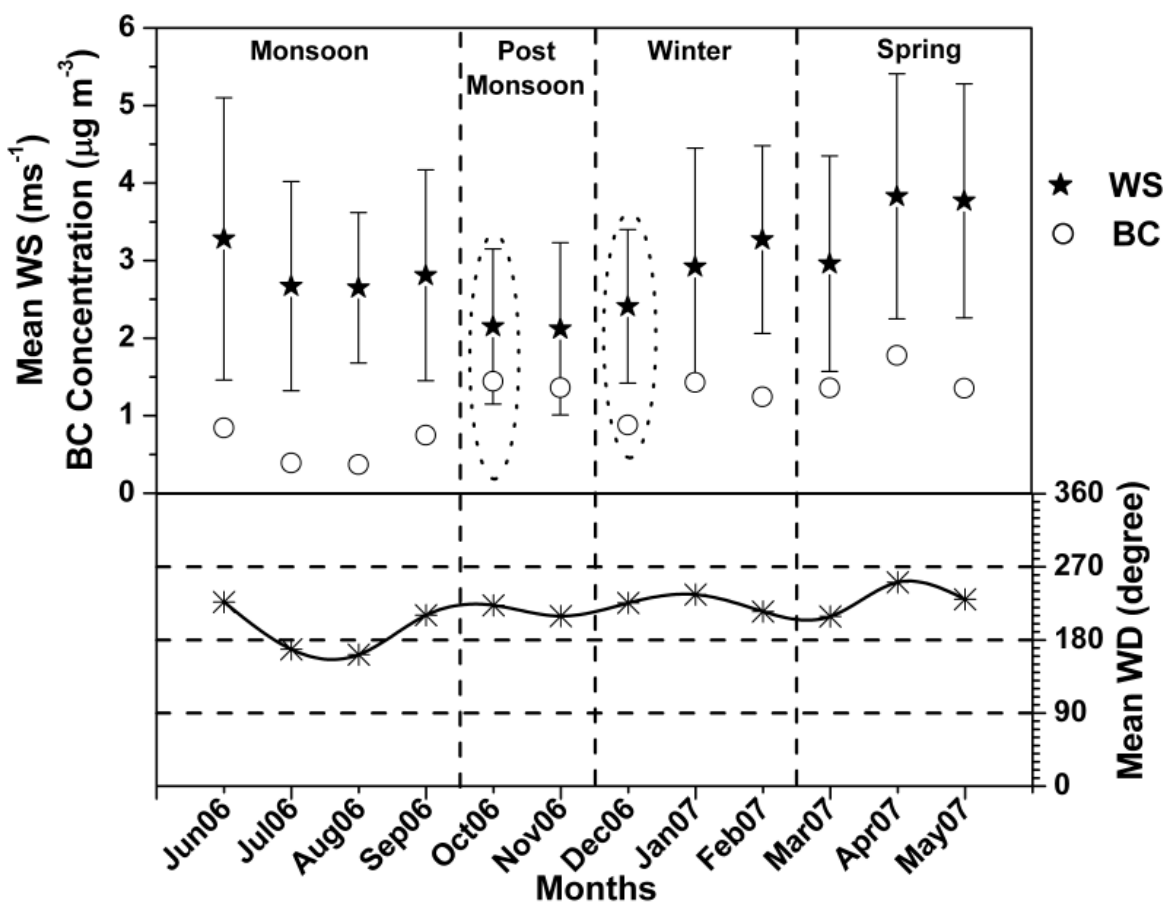

Figure 4: Monthly mean variations of wind speed and $\mathrm{BC}$ mass concentration (upper panel) and wind direction (lower panel).

\section{Radiative forcing due to BC aerosols}

As a usual convention, the forcing is represented due to the composite aerosols but in the present study, forcing was estimated due to presence of $\mathrm{BC}$ aerosols alone by neglecting other aerosol components as the exact forcing is also affected by how the $\mathrm{BC}$ aerosols are mixed with other aerosol constituents (Jacobson 2001). In order to describe the implications of $\mathrm{BC}$ aerosols alone over the radiative forcing, the measured $\mathrm{BC}$ values have been introduced as an input parameter to the optical properties of aerosol and cloud (OPAC) model given by Hess et al.(1998). Thus the important optical parameters such as aerosol optical depth (AOD), single scattering albedo (SSA) and asymmetry parameter were estimated at different wavelengths in short wave (SW) region. For this, we have followed an approach given by Moorthy et al. (2005) by using measured BC mass concentration alone as anchoring points in a standard continental average aerosol model while neglecting the other types of aerosol in the model, which is then fine-tuned to match the measurements. The measured $\mathrm{BC}$ was used to represent as soot particles in the model. $\mathrm{BC}$ aerosol optical parameters deduced from the OPAC model were then fed into the Santa Barbara DISORT Atmospheric Radiative Transfer (SBDART) model given by Ricchiazzi et al. (1998) for BC aerosol forcing estimations. The other important input parameters required in SBDART model are solar geometry, a model atmosphere and surface albedo. On the basis of prevailing weather conditions and the measured meteorological parameters, mid-latitude summer atmospheric model was used in the present case. However, the albedo of the surface over the station was considered as vegetation type among all the existing surface types in SBDART model. Diurnal average aerosol radiative forcing at the top-of-atmosphere (TOA) and at the surface is estimated by computing the 
difference in the net radiative fluxes (down minus up) with and without aerosols at their respective levels (Moorthy et al. 2005; Srivastava et al.2010). The difference between the TOA and surface forcing is considered as atmospheric forcing $(\Delta \mathrm{F})$, which represents the amount of energy trapped or absorbed by the aerosols within the atmosphere and gets transformed into heat.

Figure 5 shows monthly variation of BC aerosol forcing at the TOA, surface and in the atmosphere. TOA forcing was observed to be varying from about +3 to $+7 \mathrm{Wm}^{-2}$ over the station, indicating net warming effect. On the other hand, surface forcing, which is the net flux received at the surface after passing through the atmosphere, was observed to be negative (ranging from -6 to $-14 \mathrm{Wm}^{-2}$ ), indicating net cooling effect. The resultant atmospheric forcing due to $\mathrm{BC}$ aerosols was found to be positive (ranging from +8 to $+21 \mathrm{Wm}^{-2}$ ) over the station, implies net warming effect. The forcing values are highly associated with the BC mass concentrations in each month, which is more pronounced in the month of April and less during August. Relatively high forcing was observed during April $\left(+7,-14,+20 \mathrm{Wm}^{-2}\right.$, respectively at TOA, surface and atmosphere), which attributes due to the higher $\mathrm{BC}$ mass concentration $\left(1.8 \mu \mathrm{g} \mathrm{m}^{-3}\right)$. The direct effect of positive atmospheric forcing can intensify lowlevel inversion, which slow down convection and in turn inhibits cloud formation (Sreekanth et al. 2007). The annual mean forcing values at the TOA, surface and in the atmosphere was found to be about $+5( \pm 1),-10( \pm 3)$ and $+15( \pm 4) \mathrm{Wm}^{-2}$, respectively.

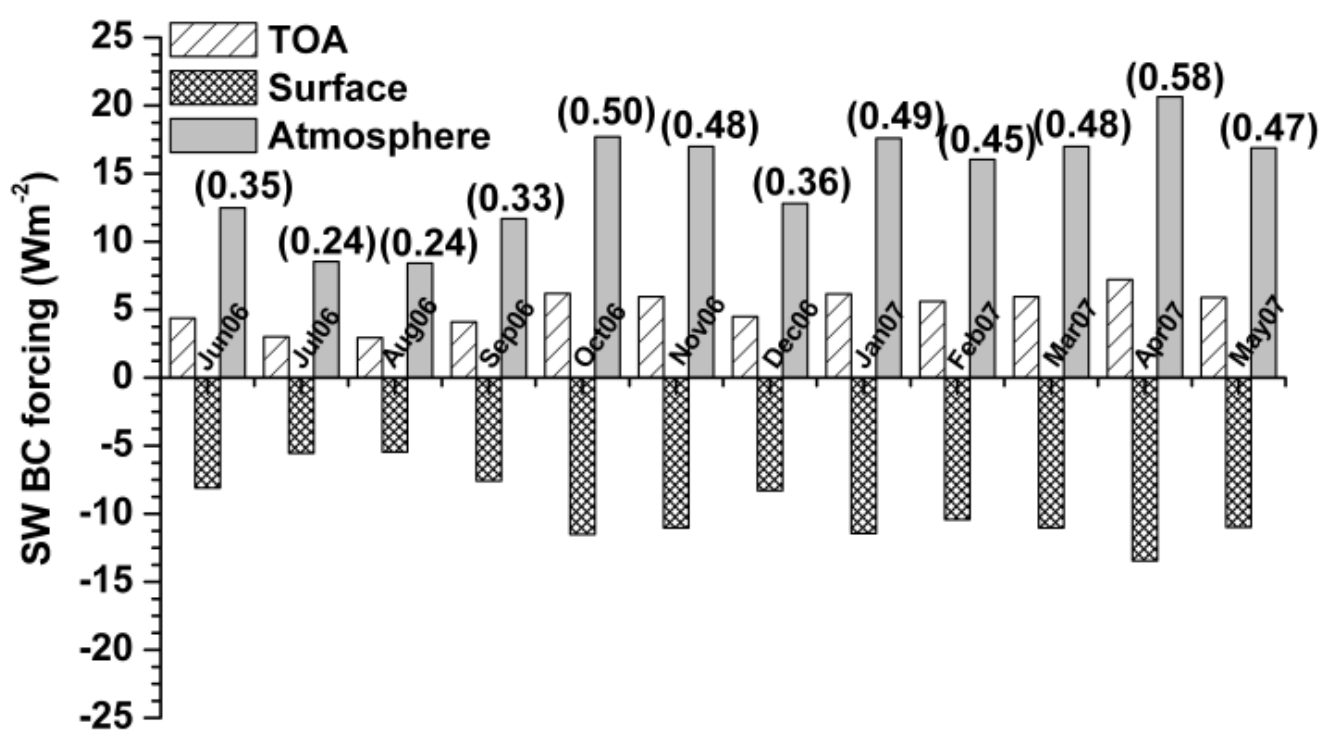

Figure 5: Monthly mean variations of shortwave radiative forcing due to $\mathrm{BC}$ aerosols (in $\mathrm{Wm}^{-2}$ ) at the TOA, surface and in the atmosphere (corresponding heating rate values are given in the parentheses in $\mathrm{Kday}^{-1}$ )

The atmospheric heating rate due to $\mathrm{BC}$ aerosols was also calculated for different months, which is shown in the parentheses in Figure 5. It also indicates its dependence on the abundance of $\mathrm{BC}$ mass concentrations. Large atmospheric heating $\left(\sim 0.58 \mathrm{Kday}^{-1}\right)$ was observed in the month of April, which corresponds to the pronounced atmospheric forcing. However, less heating $\left(\sim 0.24 \mathrm{Kday}^{-1}\right)$ was observed in the months of July and August. The annual mean heating rate at 
Nainital was found to be about $0.41 \pm 0.11 \mathrm{Kday}^{-1}$, which was significantly lower as compared to the value $\left(0.56 \mathrm{Kday}^{-1}\right)$ observed by Sreekanth et al. (2007) at Visakhapatnam.

Though the atmospheric heating rate over Nainital is comparatively low, this amount of atmospheric heating has also been conjectured as potential factor causing global warming.

\section{Conclusions}

Surface BC mass concentration measurements were carried out at Nainital from June 2006 to May 2007 using Aethalometer. The salient results are:

Significant diurnal variations in $\mathrm{BC}$ mass concentration were observed in all the seasons except monsoon, with single enhanced peak value of $\sim 2.1( \pm 0.4), 2.5( \pm 1.0)$ and $2.0( \pm 0.6) \mu \mathrm{g}$ $\mathrm{m}^{-3}$ around 17:00 hr local time during post monsoon, winter and spring, respectively which is strongly associated with the boundary layer dynamics.

Low BC concentration was observed in the month of August $\left(\sim 0.4 \pm 0.1 \mu \mathrm{g} \mathrm{m}^{-3}\right)$ due to enhanced rain washout activities; however, high $\mathrm{BC}$ was observed during April $\left(\sim 1.8 \pm 0.8 \mu \mathrm{g} \mathrm{m}^{-}\right.$ $\left.{ }^{3}\right)$. BC values are highly associated with the fluctuations in surface temperatures and winds.

Surface winds over the station generally show positive association with BC mass concentrations, which was found to be opposite at the other low altitude stations. It clearly indicates transport of $\mathrm{BC}$ from distant sources as the observing site is located at a high altitude and sparse from the proximity of $\mathrm{BC}$ sources. Back-trajectory analysis substantiates the sources of $\mathrm{BC}$, which are transported mostly as continental type air mass and reached over the station passing through the IGB regions.

The mean BC mass concentration was observed to be $\sim 0.6( \pm 0.2), 1.4( \pm 0.1), 1.2( \pm 0.3)$ and $1.5( \pm 0.3) \mu \mathrm{g} \mathrm{m}^{-3}$ during monsoon, post monsoon, winter and spring seasons, respectively. However, the annual mean BC mass concentration at Nainital was found to be $\sim 1.1( \pm 0.5) \mu \mathrm{g} \mathrm{m}^{-3}$.

$\mathrm{BC}$ forcing at TOA, surface and in the atmosphere was observed to be varies from about +3 to $+7,-6$ to -14 and +8 to $+21 \mathrm{Wm}^{-2}$, respectively at Nainital, which corresponds to the heating rate ranging from 0.24 to $0.58 \mathrm{Kday}^{-1}$. $\mathrm{BC}$ forcing and resultant atmospheric heating is more pronounced during spring and less during monsoon, which is largely associated with the BC aerosol loading.

The annual mean forcing due to $\mathrm{BC}$ aerosols at TOA, surface and in the atmosphere was found to be about $+5( \pm 1),-10( \pm 3)$ and $+15( \pm 4) \mathrm{Wm}^{-2}$, respectively which corresponds to the annual atmospheric heating rate of $\sim 0.41( \pm 0.11)$ Kday $^{-1}$.

\section{Acknowledgements}

Sincere thanks are due to the Director IITM, Pune and ARIES, Nainital for their kind support and encouragement. 


\section{REFERENCES}

[1] Babu, S. S. and Moorthy, K. K., Aerosol black carbon over a tropical coastal station in India. Geophysical Research Letter, 29(23), 2098, doi:10.1029/2002GL015662, 2002.

[2] Babu, S. S., Satheesh, S. K. and Moorthy, K. K., Aerosol radiative forcing due to enhanced black carbon at an urban site in India. Geophysical Research Letter, 29(18), 1880, doi:10.1029/2002GL015826, 2002.

[3] Hansen, A. D. A., Rosen, H. and Novakov, T., The aethalometer- An instrument for the real-time measurement of optical absorption by aerosol particles. Sci. Total Environ. 36, 191-196, 1984.

[4] Hess, M., Koepke, P. and Schultz, I., Optical properties of aerosols and clouds: The software package OPAC. Bulletin of American Meteorological Society, 79, pp. 831-844, 1998.

[5] Jacobson, M. Z., Strong radiative heating due to mixing state of black carbon on atmospheric aerosols. Nature, 409, 695-697, 2001.

[6] Latha, K. M. and Badarinath, K. V. S., Black carbon aerosols over tropical urban environment-A case study. Atmospheric Research, 69, 125-133, 2003.

[7] Moorthy, K. K., Babu, S. S. and Satheesh, S. K., Aerosol characteristics and radiative impacts over the Arabian Sea during the inter-monsoon season: Results from ARMEX Field campaign. Journal of Atmospheric Science, 62, pp. 192-206, 2005.

[8] Pant P., Hegde, P., Dumka, U. C., Sagar, R., Satheesh, S. K., Moorthy, K. K., Saha A. and Srivastava, M. K., Aerosol characteristics at a high-altitude location in central Himalayas: Optical properties and radiative forcing. Journal of Geophysical Research, 111, D17206, doi:10.1029/2005JD006768, 2006.

[9] Ramachandran, S. and Rajesh, T. A., Black carbon aerosol mass concentrations over Ahmedabad, an urban location in western India: Comparison with urban sites in Asia, Europe, Canada, and the United States. Journal of Geophysical Research, 112, D06211, doi:10.1029/2006JD007488, 2007.

[10] Reddy, M. S. and Venkataraman, C., Direct radiative forcing from anthropogenic carbonaceous aerosols over India. Current Science, 76, 1005-1011, 1999.

[11] Ricchiazzi, P., Yang, S., Gautier, C. and Sowle, D., SBDART: A research and teaching software tool for plane-parallel radiative transfer in the earth's atmosphere. Bulletin of American Meteorological Society, 79, pp. 2101-2114, 1998.

[12] Sagar, R., Kumar, B., Dumka, U. C., Moorthy, K. K. and Pant, P., Characteristics of aerosol spectral optical depths over Manora Peak: A high altitude station in the central Himalayas. Journal of Geophysical Research, 109 (D06207), doi:10.1029/2003JD003954, 2004.

[13] Safai, P. D., Kevat, S., Praveen, P. S., Rao, P. S. P., Momin, G. A., Ali, K. and Devara, P. C. S., Seasonal variation of black carbon aerosols over a tropical urban city of Pune, India. Atmospheric Environment, 41, 2699-2709, 2007. 
[14] Sreekanth, V., Niranjan, K. and Madhavan, B. L., Radiative forcing of black carbon over eastern India. Geophysical Research Letter, 34, L17818, doi:10.1029/2007GL030377, 2007.

[15] Srivastava, A. K., Pant, P., Hegde, P., Singh, S., Dumka, U. C., Naja, M., Singh, N., and Bhavanikumar, Y., Influence of south Asian dust storm on aerosol radiative forcing at a high-altitude station in central Himalayas. International Journal of Remote Sensing (Accepted), 2010.

[16] Tripathi, S. N., Dey, S., Tare, V. and Satheesh, S. K., Aerosol black carbon radiative forcing at an industrial city in northern India. Geophysical Research Letter, 32, L08802, doi:10.1029/2005GL022515, 2005. 